\title{
"The Cyclone which is at the Heart of Things": The cyclone as trope of place and apocalypse in Queensland literature
}

\section{Chrystopher Spicer}

Humanities; College of Arts, Society and Education, James Cook University, Australia

\begin{abstract}
In order to better understand and respond to the tropics as part of the global environment, we need to accept the unique features of the regional weather, such as cyclones, and be prepared to embrace their larger meaning for life in the tropics. In a physical landscape impacted by some 207 tropical cyclones since 1858, Queensland writers have attempted to incorporate both the terror and the sublime of the cyclone into their sense of place as they have attempted to find context for the unpredictable, chaotic and destructive tropical cyclone within their ostensibly tamed and ordered natural landscape. Consequently, the cyclone has become a defining symbolic metaphor of not only physical but also of literary tropical Queensland.
\end{abstract}

Some Queensland writers have perceived within cyclones the Burkean sublime or personal revelation, while others have seen it as motivation for community strength, cooperation and compassion. For some, the purpose of the cyclone is divine retribution, but to others it's an apocalyptic event revealing a rare second chance for revelation and renewal. This paper will examine a range of such perceptions within Queensland literature as part of the search for meaning within cyclonic chaotic events.

\section{Tropes and cyclones}

In Meteorologica, Aristotle theorized that there were only two habitable areas of the earth: one near the northern pole region and the other near the southern pole. Within the latitudes of the Tropics of Cancer and Capricorn, no-one could live (II. v. 362a. p.181). He also suggested that somewhere on the other side of the world in the southern hemisphere, "there must be a region which bears to the other pole the same relation as that which we inhabit bears to our [northern] pole" (II. v. 362b. p. 183). The passing of time and further exploration eventually proved the ancient philosopher right about a Southern continent, but he could not have been more wrong about that area between the Tropics of Cancer and Capricorn now known as 'the tropics.' Contrary to Aristotle's predictions about being uninhabitable, the tropical region is 
currently home to some $40 \%$ of the world's population and $80 \%$ of the planet's terrestrial biodiversity (State of the Tropics, 2014, p. 4), and it continues to develop; by 2050 approximately 55\% of the world's population will live in the tropics (Harding, 2011,

p.2). However, the region is also home to extreme weather conditions, and one of the most significant atmospheric phenomena affecting this region is the tropical cyclone which, through a combination of high-speed winds, heavy rain and storm surges, can be severely destructive. Maximum wind gusts within these rotating storms can reach $300 \mathrm{~km} / \mathrm{h}$, rainfall has been recorded up to $1000 \mathrm{ml}$ in 24 hours, and storm surges have raised sea levels ten metres, resulting in loss of life and destruction of property, sometimes on a large scale (State of the Tropics, 2014, p. 48). Occurring with cyclical seasonal regularity, such storms are historically endemic to the tropical region and consequently have been integrated into its life, culture and literature. To live successfully in the tropics, then, one must not only accept the storm as an integral part of life but be prepared to heed the meaning of the storm, to embrace new worlds revealed by it and so comprehend more about the relationship between person, people and biosphere in order to "better understand and better enable the tropical world" (Harding, 2011, p. 4).

William Strachey (1610), cast onto the virginal shores of the island of Bermuda in 1609 as a survivor of the wreck of the Sea Venture, later wrote in his True Reportory of the Wracke that, "These llands are often afflicted and rent with tempests, great strokes of thunder, lightning and raine in the extreamity of violence. . . which keepe their unchangeable round, and rather thunder then blow from every corner about them, sometimes fortie eight hours together" (Strachey as cited in Murray, 1991 p. 91). As in other tropical areas, such as the Caribbean, cyclones are also endemic to the North Queensland coast which has been affected by some 200 of them since 1858: an average of between four and five every year. Part of the regional year there, in fact, is known as the 'cyclone season.' So, North Queenslanders necessarily established an early, significant and personal relationship with this unique weather event, such that tropical cyclones have become an integral aspect of the history, culture and the literature of the region. Cyclones, by their very nature unpredictable, uncontrollable and unavoidable, are part of coastal Queensland life.

So thorough was that early inclusion, in fact, that a Queensland meteorologist was the first to systematically name cyclones when, on 20 September 1894, Clement Wragge, the Queensland Government Meteorologist and Superintendent of the Chief Weather Bureau in Brisbane, gave the name 'Beta' to a cyclonic storm approaching Lord Howe Island. Although the word 'cyclone' had been in frequent use since it had first been coined in 1848 by Henry Piddington in his Sailors Hornbook for the Law of Storms, there was still much confusion about appropriate application of the name until well into the twentieth century; even Wragge frequently reverted to the generic term 'disturbance' when referring to them. He had decided to begin naming tropical weather depressions after the letters of the Greek alphabet in order to be able to distinguish them on his increasingly sophisticated weather maps that were being published daily. So cyclones, previously traditionally named according to the day or place of landfall, could now not only be distinguished from each other, but were imbued with individual human personality. In this way, Wragge was the earliest known European Australian to reveal that cyclonic storms have an impact on the imagination as well as on the landscape. "What a 
grand meteorological opera is in progress!" he wrote in March, 1898, as he informed readers along the Queensland coast between Bundaberg and Ballina that they could soon be enjoying the "stirring music" of the south-western edge of Hurricane Sana approaching them across the Pacific after devastating New Caledonia:

The sea in sympathy and its stentorian bass to the whirring of the wind, anon roaring around some cavernous bluff, then lashing the cliffs in angry tones with supernal cascades of majestic beauty - while modulating the sonata, in turn, to the hissing, seething notes of bubbling foam. In New Caledonia . . . will 'Sana,' the storm empress of the Pacific, soon perform her marvellous evolutions, and dance her wildest step. (“Fantastical Forecast," p. 3)

Wragge endows his "storm empress" with emotive and personified allegories of music and dance, associating both with the sublime in tune with Edmund Burke's (1992/1757) interpretation some 140 years earlier in his A Philosophical Enquiry in which he proposed that, Whatever is fitted in any sort to excite the ideas of pain, and danger, that is to say, whatever is in any sort terrible, or is conversant about terrible objects, or operates in a manner analogous to terror, is a source of the sublime; that is, it is productive of the strongest emotion which the mind is capable of feeling. I say the strongest emotion, because I am satisfied the ideas of pain are much more powerful than those which enter on the part of pleasure. (p.36)

Both Burke and Wragge were aware that nature has two sides: beauty and pleasure, terror and pain. Wragge knew that cyclones can provoke such emotions; he too could see the sublime within that whirling storm.

It is not surprising, then, that cyclones feature prominently as image and trope throughout the history of Queensland literature, just as cyclonic storms have featured historically in the literature of other tropical regions and beyond. For instance, in the works of Shakespeare's The Tempest (1977/1610-11) which famously referenced the 1609 shipwreck of the Sea Venture in a hurricane off the coast of Bermuda, some survivors of which eventually settled the island; Daniel Defoe's The Storm (2005/1704) that provides an account of the savage North Atlantic hurricane that devastated the British Isles in 1703; Joseph Conrad's 1902 tale of the Siamese steamer Nan-Shan's encounter with a storm in the China Seas in Typhoon (1975); Richard Hughes' controversial 1929 novel High Wind in Jamaica (1971) in which children struggle to survive being taken by pirates after a hurricane destroys their home; African-American author Zora Neale Hurston's 1937 novel Their Eyes Were Watching God (1986), based on events surrounding the Okeechobee Hurricane of 1928 in Florida; George R. Stewart's Storm (1941) renowned for being the first American novel to give a personal name to a cyclonic storm, and Jamaican author Diana McCaulay's Huracan (2012). Cyclonic storms have also featured in poetic works such as British poet Anne Finch's Upon the Hurricane (1713), the American writer William Cullen Bryant's The Hurricane (1853), William Hamilton Hayne's A Cyclone at Sea (1892), Adrienne Rich's Storm Warnings (1951), Hart Crane's The Hurricane (1993), Teresa Cader's History of Hurricanes (2009), Australian writer A.B. 'Banjo' Patterson's The Ballad of the Calliope (1902), and Caribbean poet Kamau Braithwaite's Shar: Hurricane Poem (1990). 
Yet, while these works are well known in the international literature of storms, no comprehensive research has yet been carried out in Queensland to identify literary works that feature cyclonic storms and so recognize the significance and continuity of the cyclonic trope within Queensland literature, although a number of Queensland writers since Wragge have sought to incorporate cyclones into the literary landscape and the Queensland sense of place. To date, my research has identified the cyclonic trope within at least ten novels, sixteen short stories, seventeen poems and over a dozen published literary accounts of cyclones, either written by authors born in Queensland or located in that state, thus revealing a rich heritage of cyclone writing in Queensland literature.

My aims in this research are on the one hand to demonstrate that the cyclone has been used as a trope throughout the history of Queensland literature, becoming incorporated into Queenslanders' landscape and sense of place. On the other hand, I also want to propose that this trope is used by Queensland writers as a metaphor for revelatory apocalypse, which in its ultimate form Morton Paley (1986) terms the "apocalyptic sublime" (p.1), a destructive event so terrible that it excites, as Burke (1992/1757) put it, the strongest imaginative emotions. The term 'apocalypse' derives from the Greek apokalupsis, implying an unveiling and realisation of future events or meanings: a revelation. The Biblical God spoke out of the whirlwind to Job (40:6 KJV), and in Queensland literature there is frequent reference to the cyclone as an instrument of divine will, of fate or destiny, revealing to people individually and collectively that they are part of the inevitable and uncontrollable cycle of death and birth, of change and renewal. So, the great spinning wheel of the cyclone as a trope in Queensland literature is about more than the weather; it is about the cycle of life itself. Those caught up in the cyclone seek the meaning of it and in it as they seek to integrate the experience as part of their lives.

\section{The literary cyclone experience}

The cyclone is an integral part of the natural tropical seasonal cycle, a perpetual possibility that continually reminds us of our actual place in the universe. "Truly, at the best, our apparent safety is but insecurity and our boasted power is but impotence," observed Mrs Porter, one of the few survivors of the catastrophic Cyclone Mahina that struck the Cape Melville area in Far North Queensland in 1899, wiping out the Torres Strait pearling fleet and killing some 400 people. "We speak at times as though we are conquering Nature," she continued, "but the God of Nature speaks and . . . our scientific knowledge is of no avail to enable us to escape the gathering storm." (Outridge, 1899, p.31).

Like Mrs Porter, North Queenslanders recognize that cyclones have the power to be more than just weather events; they have the power to change lives. Cyclones are the chaos that devastates the structure of everyday life and in seeking to know a reason for that chaos, people impart to a cyclone the qualities of apocalypse, the ultimate revelation. As James Berger notes in his book, After the End (1999), to be truly apocalyptic an event must in its disruption clarify and illuminate "the true nature of what has been brought to end (p. 5)." Rather than just being the end in itself, he explains, the apocalypse anticipates, reveals and explains the end. To seek an answer to such an event, then, is to seek revelation from the storm itself, the storm that has destroyed the old and, in doing so, reveals the new. 


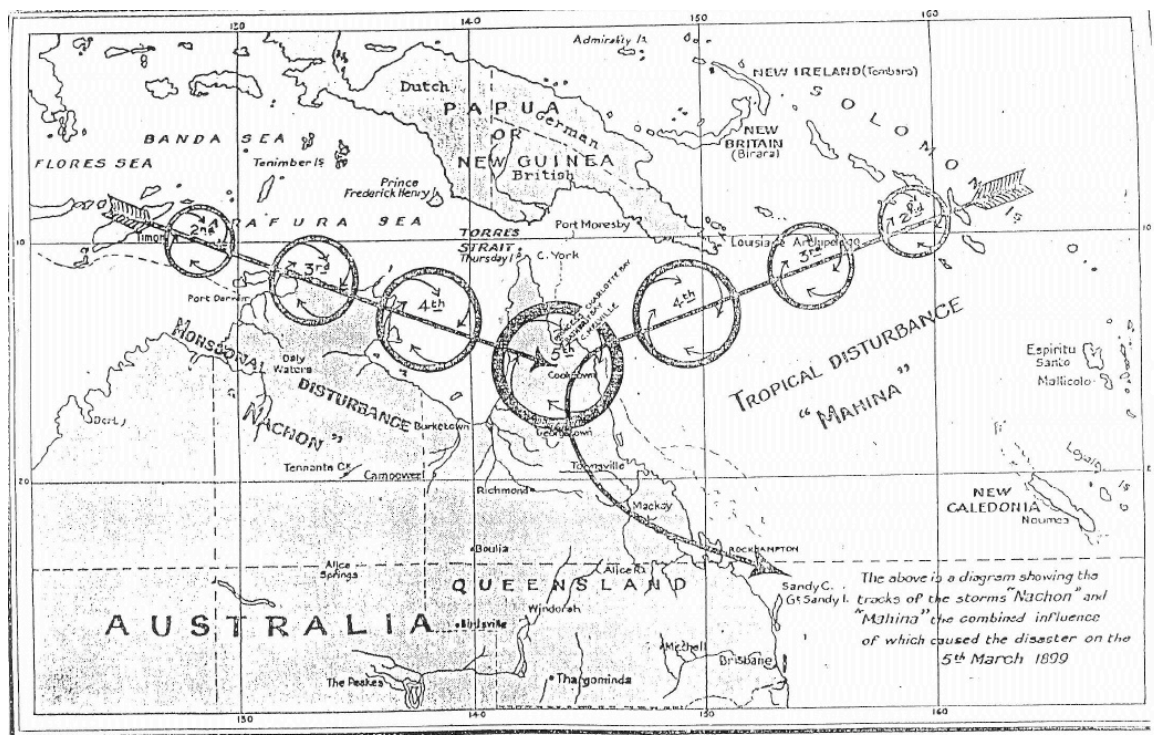

Figure 1. Map showing the path of Cyclone Mahina, the 1899 Category 5 storm that caused the greatest number of fatalities in the history of Australian natural disasters. Outridge Printing Co.

So, throughout Queensland literature the cyclone appears accordingly as both destroyer and re-creator, as such apocalyptic events reveal opportunities to start again. In this way, the incomprehensible can be comprehended and the meaningless given meaning. Some revelations of meaning may be intensely personal, as Susan Hawthorne (2009) observes in her poem, "Wind Mind":

I am in with through the cyclone
which is inside with through me
the cyclone which is at the heart of things
the cyclone which is at the edge of chaos
we too are like the swirling objects
in a Remedios Varo painting
twirling spiralling simultaneously
at the edge and at the centre of the
universe in a massive creation of life. (Earth's Breath, p. 78)

Here, Hawthorne connotes the internal cyclone as well as the external, suggesting that we are all part of the same elemental universe in which such storms may impact intimately on our physical and personal landscape, stripping away our outer personal layers as well as the roofs above us, revealing what has previously been hidden. In Thea Astley's A Boatload of Home Folk (1968), a group of people stranded on a South Pacific island by a cyclone have no choice but to face not only the outer cyclone but also their internal storms, revealing that which is within. As the storm whirling on the outside strips away the layers of the island buildings, so it also strips away the layers of the group's characters to reveal the loneliness, shallowness, absurdity and unhappiness beneath, revealing their flawed humanity. Some do not survive such an exposure, while others emerge changed by it. 
In exposing hidden faults and fears, the cyclone can inspire individuals to overcome those fears. At the end of Vance Palmer's 1932 story The Big Wind, for example, the abandoned wife Mary, who has had to cope with birthing a child in the middle of a cyclone, declares: "I won't be afraid of wind again. Afraid of anything else, either. You just clench your teeth and at last you come out on the other side" (p.13). Fifty years later, the determination to survive the tropical environment remains. The apocalypse of Cyclone Harry reveals to newcomer Lucy Morton, who is left home alone with three children in Meredith Traherne's 1982 story Cry of the Wild Wind, that she has the strength and courage with which to overcome her fears of a new environment and deal with adversity in her new home of North Queensland.

The tropical cyclone experience can also inspire individuals to survive and recover by working together, finding strength in community. As a result of the storm in Vance Palmer's (1947) novel Cyclone, the entire town experiences an epiphany. Whereas before the storm they were lethargic, so self-centred and consumed with appearances they were ready to forcibly evict the unemployed, afterwards it was as though "with the passing of the storm some conflict had been resolved, some cord of tension relaxed" (p. 190), and there is renewed optimism and a new-found sense of support and co-operation in the town. Similarly, in her short story Monsoon Two, Esther Knight (2008) observes that the next few days after the storm "brought a flood of compassion. Many local people, who had suffered damage themselves, left their homes and farms to help others. Armed with chainsaws and tools, "they just quietly entered streets . . . and generally did what they could" (p. 25).

In this way the cyclone, as well as other types of cyclonic storm, re-affirms people's cohesive status within their cultural landscape as a group that has endured a unique experience. The stories that they tell of their experience are stories only they can truly share, through which the very uniqueness of that experience is conveyed to others. In repeating these stories among themselves, to others, and on through successive generations - people continue to re-affirm relationships between the cyclonic storm, themselves, their landscape and their culture, and in doing so they integrate and reconstruct into their lives that which could have been potentially destructive. Such a significant acceptance and integration is an important recognition of personal relationship to a weather event that, by its very seasonal repetition, perpetuates itself within the culture of tropical regions. Each type of tropical cyclonic storm, whether cyclone, hurricane, or the divine wind of a typhoon, has an impact on the regional imaginary that is specific and unique to the nature, history and culture of that region. The stories of the tropical cyclone, then, are significant to that regional sense of place just as the stories of tropical cyclonic storms are inherent to an understanding of the tropics themselves.

\section{Senses of terroir}

Ever since the ancient Greeks stamped amphorae with the seal of the region from which they came, the producers of foodstuffs such as wine, coffee, tea and cheese have recognised the existence of terroir, the combination of geography, geology and climate with plant genetics that imparts particular characteristic regional qualities to that product. Like good wine and cheese, literature also has terroir: the land where the literature is created and developed nourishes it and imparts unique qualities to it. Thus literature can be influenced by regional 
factors beyond the control of human hands, qualities that give literature a sense of place. But place as terroir is more than just locality; it is, as Frank Vanclay (2008) observes, "space imbued with meaning"(p. 3), a space in which meanings are invested other than those relating to its physical elements.

Ultimately, it is the relationship, sometimes a personal one, between the inhabitants of the region and these meanings that gives place its 'sense'. Each person associates unique meanings and use with place, and so a sense of place is individualised as much as nationalised. Terroir can be experienced by the one as well as the many; it is the terroir embedded in the senses and stories of the individual that eventually becomes the terroir of the people. "In telling stories about our places," Vanclay proposes, "we create and re-create; revise and adjust; confirm and re-confirm; affirm and re-affirm our connections to place. Storytelling, then, is a way in which any place becomes 'our place' or 'our patch' where we assert some authority, or ownership, or at least some connection to a place" (2008, p. 5).

Stories enable people to place themselves within a universe that has shape and sense, to know their relationship to it and that their lives have meaning within it, even though that universe may contain uncontrollable elements. Stories are not only about place but of place; they not only form place but are in fact formed by the place itself. According to Merrill Findlay (2008), Michel Foucault observes that stories "systematically form the objects of which they speak" (p. 19), becoming an actual part of that terroir. So, in telling stories about cyclones and the impact of those cyclones on lives and landscape, North Queensland and other tropical region writers are seeking to make sense of place, having encountered uncontrollable events that have rendered order and meaning unordered and meaningless. As she latches the window shutters, pulls the curtains and lights candles in the face of an oncoming storm, poet Adrienne Rich muses that, "These are the things we have learned to do/Who live in troubled regions" (2016, p.1). Such stories of catastrophe within these regions and their symbols and metaphors, writes anthropologist Susanna Hoffman, "reflect the mental processes of a collective people and the fruits of both creative impulse and sense-making reasoning" (2002, p.113). In writing about cyclonic storms, then, tropical writers are putting into words their terroir as well as their terror, forming and re-affirming a sense of terra that includes the spiritual and the imaginative as well as the physical, finding the sublime within the storm.

So close is our relationship to place, in fact, that the ancient Romans believed each place had its own spirit, the genius loci, which gave identity to that place through presence and action. Later writers such as Shakespeare made much of that tradition. Like Shakespeare's Ariel and Puck, the cyclone as spirit of North Queensland place manipulates and impacts on place and, in doing so, imbues it with identity. The cyclone experience can be a spiritual one, as Elizabeth Hunter discovers in Patrick White's (1977) Eye of the Storm. For Hunter, being in the cyclone's eye is a moment of grace and stillness for which she yearns and continues to search until her death. The eye becomes her core of reality, her true existence at the very centre of her outer layers of appearance. Not until her death, however, does she ultimately discover her truth and is granted dispensation, experiencing a final apocalyptic revelation of that beach on which she stood in the eye of the cyclone. 
Like Elizabeth Hunter, people seek to engage with, and understand, their relationship with place by contextualising the landscape as it is to them. The individual is the point from which the landscape is perceived and experienced, becoming our ego-centred place. "Landscape is never inert," Barbara Bender (1995) writes: "People engage with it, re-work it, appropriate and contest it. It is part of the way in which identities are created and disputed" (p.3). As people engage, they position themselves within their landscape in order to render it meaningful. For example, cyclones and geographic features alike are endowed with names, in order to incorporate them into the landscape of the familiar and to impose order on elements of landscape that are chaotic and random, enabling people to form patterns of experience in order to make sense of place.

It is within the context of such patterns that people constantly search for explanations, whether they relate to gods or fate, in order to cope with and survive violent, elemental and unexplainable natural events, such as cyclones, that cause extreme changes to our otherwise ordered, rational world. While for some there must be a reason, for others there never will be one, precisely because the cyclone is a force of untamed, primordial nature. Cyclones typically demonstrate that natural elements should be accepted as part of daily life, for the spiral of the cyclonic storm is the universal spiral seen in a galaxy, a DNA helix and the whorl of a seashell. As the cyclone is experienced across the geographical landscape, a regional consciousness is engendered by this common circulation of elements, and in this way the cyclone becomes a key constituent of a socio-ecological relation that roots North Queenslanders to their land and to the tropical region. Thus the cyclone can be a trope of deeper, universal meanings, as it is in Aboriginal author, Alexis Wright's 2007 novel, Carpentaria.

The two cyclones that bracket Wright's work are part of a timeless "imagined, hopeful and alternative landscape of literature" (Archer-Lean, Carson \& Hawkes, 2013, p. 30) within which Wright shapes the possibility of a new future for the landscape's inhabitants, while she imagines new ways for readers to develop an appreciation of it. "The ancestral serpent," she begins,

a creature larger than storm clouds, came down from the stars, laden with its own creative enormity.... It came down, those billions of years ago, to crawl on its heavy belly, all around the wet clay soils in the Gulf of Carpentaria.... They say its being is porous; it permeates everything. It is all around in the atmosphere and is attached to the lives of the river people like skin (2007, pp.1-2).

Yet this has become a landscape of apparent hopelessness for a people whose last hope is in stories. "Anyone can find hope in the stories," the elders remember, "the big stories and the little ones in between" (Wright, 2007, p. 12). After the apocalypse of the second cyclone there is hope of a new landscape, a promise symbolised by earlier, seemingly miraculous events: thousands of seagulls hovering in the sky before a storm, atmospheric conditions that cause all the clocks in the town of Desperance to stop, and the Messianic vision of prophet-like Elias Smith who seems to walk across the water towards the townspeople after the first storm, reminiscent of diviner Michael Random's appearance in the desert outside of Randolph Stow's (1965) imaginary town of Tourmaline. 
In the novel, Smith, like Random, is a tabula rasa, a blank slate on whom people will write their stories of hope, of loss and of storms to come. As Wright's Aboriginal elders say, "Cyclones don't come from nowhere, because there is plenty of business going on when cyclones come onto the country out of the rooftop of the world" (2007, p. 479), and in this landscape there is indeed "plenty of business" concerning cyclones. As the final cyclonic flood surge obliterates the town of Desperance, Will Phantom realises "how history could be obliterated when the Gods move the country. He saw history rolled, reshaped, undone and mauled as the great creators of the natural world engineered the bounty of everything man had ever done in this part of the world into something more of their own making" (2007, p. 492). As a true instrument of apocalypse, Wright's cyclone destroys landscape but also rebuilds and renews it. At the novel's end, there is "so much song wafting off the watery land, singing the country afresh" (p. 519), as Will and his son walk home. This cyclone is a spiritual as well as a physical experience that brings together the conscious with the unconscious in the landscape of the mind, and in this way Carpentaria imagines new ways of understanding relationship with the physical, natural landscape.

The cyclonic storm in Queensland literature reverberates, therefore, with contexts of theme and setting, plot and trope, of political ecology and geopolitics that encompass the complicated and symbiotic relations between society, nature, landscape, place and space. The metaphorics and aesthetics of tropical cyclones permeate Queensland literature, disrupting the space and time of the structured human everyday, regularly reminding Queenslanders that the natural order prevails rather than the imposed orders of civilization. As they do in this region, apocalyptic tropical cyclones cleanse traditional society structures, stripping away the historic human over-growth, leaving new life room to re-build and grow. They can narrate resilience in the face of natural disaster and allegorize the power of cultural consciousness to strengthen and unify communities and regions so that people can emerge from the experience transcended, transformed. The literary tropical cyclone challenges human experience, providing opportunity to move forward and rebuild, providing opportunity for the emergence of the new. As tropical regions continue to develop, so will the challenges of living within them. Some challenges, like the weather, may not be issues humankind can solve, but rather will be challenges with which we must learn to live, and one of the ways in which this can happen is through the shared literary experience. In living within the community of the tropical region, we not only accept the cyclonic storm as an integral part of life but we should also be prepared to heed the epiphanies and revelations of such storms, for we better understand and enable our developing tropical world by embracing new worlds revealed by the storm. In this way, we broaden our perception of the relationship between the individual, society and the tropical biosphere.

\section{References}

Archer-Lean, C., Carson, S.J., \& Hawkes, L. (2013). Fiction as a form of change: A paper overview of a literature panel discussion. In S. Davis (Ed.), Future nature future cultures (pp. 29-36). Noosa, Australia: Noosa Biosphere Limited and Central Queensland University. 
Aristotle (1978). Meteorologica (H. D. P. Lee, Trans.). In G. P. Goold (Ed.), Aristotle in twenty-three volumes, (Loeb Classical Library, Vol. VII). London, United Kingdom: William Heinemann.

Astley, T. (1968). A boatload of home folk. Sydney, Australia: Angus \& Robertson.

Bender, B. (Ed.). (1995). Landscape: Politics and perspective. Oxford, United Kingdom: Berg Publishers.

Berger, J. (1999). After the end: Representations of post-apocalypse. Minneapolis, MN: University of Minnesota Press.

Burke, E. (1992). A Philosophical enquiry into the origin of our ideas of the sublime and beautiful. (A. Phillips, Ed.). Oxford, United Kingdom: Oxford University Press. (Original work published 1757).

Brathwaite, E.K. (1990). Shar: Hurricane Poem. Mona, Jamaica: Savacou Publications.

Cader, T. (2009). History of hurricanes. In History of hurricanes (pp. 3-5). Evanston, IL.: Northwestern University Press.

Conrad, J. (1975). The nigger of the narcissus/Typhoon/and other stories. Harmondsworth, United Kingdom: Penguin.

Fantastical Forecast: Mr Wragge's Prophecy. (1898, 3 March). Bairnsdale Advertiser and Tambo and Omeo Chronicle, 3.

Findlay, M. (2008). Understanding place through narrative: Using stories to change the places we love and who we are. In F. Vanclay, M. Higgins, A. Blackshaw (Eds.), Making sense of place: Exploring concepts and expressions of place through different senses and lenses (pp. 13-21). Canberra, Australia: National Museum of Australia Press.

Crane, H. (1993). The Hurricane. In M. Simon (Ed.), The complete poems of Hart Crane. New York, NY: Liveright Publishing.

Defoe, D. (2005). The Storm (R. Hamblyn, Ed.). London, United Kingdom: Penguin.

Finch, A. (1999). Upon the hurricane. In D. Fairer \& C. Gerrard (Eds.), Eighteenth century poetry: The annotated anthology (pp. 26-33). Oxford, United Kingdom: Blackwell.

Harding, S. (2011). The tropical agenda. Journal of Tropical Psychology, 1(1), 2-5. DOI:10.1375/jtp.1.1.2

Hawthorne, S. (2009). Earth's breath. Melbourne, Australia: Spinifex Press.

Hayne, H. (1900). A cyclone at sea. In E.C. Stedman (Ed.), An American Anthology, 1787-1900 (p. 613). Boston, MA: Houghton, Mifflin \& Co.

Hoffman, S. M. (2002). The monster and the mother: The symbolism of disaster. In S.M. Hoffman \& A. Oliver-Smith (Eds.), Catastrophe \& culture: The anthropology of disaster (pp. 113-141). Santa Fe, NM: School of American Research Press.

Hughes, R. (1971). A high wind in Jamaica. London, United Kingdom: Chatto \& Windus.

Hurston, Z.N. (1986). Their eyes were watching God. London, United Kingdom: Virago.

Knight, E. (2008). Monsoon two. In The Tropical Writers of Far North Queensland (Eds.), Raining on the sun (pp. 37-39)]. Cairns, Australia: Tropical Writers of Far North Queensland.

Murray, J.A. (Ed.) (1991). The islands and the sea: Five centuries of nature writing from the Caribbean. New York, NY: Oxford University Press.

Paley, M.D. (1986). The apocalyptic sublime. London, United Kingdom: Yale University Press.

Palmer, V. (1932, 2 November). The big wind. The Sydney Mail, pp. 12-13.

Palmer. V. (1947). Cyclone. Sydney, Australia: Angus \& Robertson.

Patterson, A.B.B. (1902). The ballad of the calliope. In Rio Grande's last race and other verses (pp. 96-101). Melbourne, Australia: Angus \& Robertson.

Rich, A. (1951). Storm warnings. In A change of world (p. 1). New York, NY: AMS Press.

Rich, A. (2016). A change of world. New York, NY: Norton.

Shakespeare, W. (1981). The tempest. In A. Harbage, \& N. Frye (Eds.), William Shakespeare: The complete works (pp. 1369-1395). New York, NY: Viking Press. 
State of the Tropics (2014). State of the Tropics 2014 report. Cairns, Australia: James Cook University.

Stewart, G.R. (1941). Storm. New York, NY: Random House.

Stow, R. (1965). Tourmaline. Sydney, Australia: Penguin.

The Pearling Disaster, 1899: A memorial. (1899). Brisbane, Australia: Outridge Printing Co.

Traherne, M. (1982, 16 June). Cry of the wild wind. The Australian Women's Weekly, pp. 57-62.

Vanclay, F. (2008). Place matters. In F. Vanclay, M. Higgins, \& A. Blackshaw (Eds.), Making sense of place: Exploring concepts and expressions of place through different senses and lenses ( $\mathrm{pp}$. 3-11). Canberra, Australia: National Museum of Australia Press.

White, P. (1977). Eye of the storm. Sydney, Australia: Penguin.

Wright, A. (2007). Carpentaria. Artarmon, Australia: Giramondo. 